\title{
Multiple pulses improve electroporation efficiency in Agrobacterium tumefaciens
}

\author{
Tariq Mahmood \\ Department of Plant Sciences \\ Quaid-i-Azam University \\ Islamabad, Pakistan \\ Tel: 92514845623 \\ Fax: 92519290160
}

E-mail: taariq.mahmood@yahoo.com

Tamkina Zar

Department of Plant Sciences

Quaid-i-Azam University

Islamabad, Pakistan

Tel: 92514845623

Fax: 92519290160

S.M. Saqlan Naqvi*

Department of Biochemistry

University of Arid Agriculture Rawalpindi

Murree Road, Rawalpindi, 46300, Pakistan

Tel: 92514845623

Fax: 92519290160

E-mail: saqlan@isb.paknet.com.pk

Financial support: This study was supported by a grant No. 01-03-01-19 from Agricultural Linkages Program of the Pakistan Agricultural Research Council.

Keywords: Agrobacterium, electroporation, pulse number, transformation efficiency.

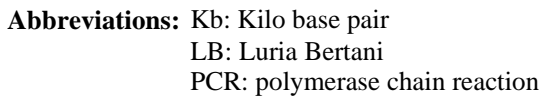

Electroporation entails brief, high intensity pulse to create transient pores in the cell membrane to facilitate the entry of exogenous macromolecules, which may otherwise be excluded. Removal of the external field leads to the resealing of the membrane electropores permitting the survival of the electrically stimulated recipient cells. Using this technique foreign deoxyribonucleic acid (DNA) has been successfully introduced into many cell types both from prokaryotes and eukaryotes. Increase in pulse voltage and length beyond a critical limit has been reported to decrease transformation efficiency, hence in this study we have investigated another strategy i.e. increase in the number of pulses at constant high voltage and pulse duration. Commonly used Agrobacterium strains LBA4404 and EHA101 and binary vector pCAMBIA1301 were used. Transformants were selected on a combination of hygromycin and kanamycin, and confirmed by polymerase chain reaction (PCR) and restriction analysis. Increase in the number of pulses was found to show a significant and linear increase in transformation efficiency.

Application of deoxyribonucleic acid (DNA) technology to genetically manipulate cellular functions requires a suitable high efficiency transformation system. There are many approaches available for introducing foreign DNA into eukaryotic and prokaryotic cells, however electroporation is the most commonly used technique and currently of more practical interest. It is a gene transfection technique, which entails brief, high intensity pulse to facilitate the entry of exogenous molecules like DNA, ribonucleic acid (RNA), and protein. Removal of the external field leads to the resealing of the membrane electropores.

Applying high intensity electric fields to reversibly permeablize biomembranes to create structural distortions, allowing the uptake of DNA was first demonstrated by Neuman in mouse myeloma cells (Neuman et al. 1982).

*Corresponding author 
Since then it has been used as a routine transformation technique. Rhee et al. (2007) have reported that in Bacillus coagulans transformation, electroporation is a better option than using chemical transformation protocols mediated by high $\mathrm{Ca}^{2+} / \mathrm{Mg}^{2+}$. There are different reports about the manipulations of electroporation conditions for increasing the transformation efficiency. Turgeon et al. (2006) evaluated the influence of modulating growth cycle, electric field and amino acid composition (glycine and threonine) to elaborate an electro-transformation procedure for Bacillus cereus to yield $2 \times 10^{9} \mathrm{cfu} / \mu \mathrm{g} / \mathrm{ml}$. Increase in transformation efficiency in response to electric field strength, pulse length, DNA quality and cell density has been documented (Myers and Tisa, 2003; Chen et al. 2006; Rodríguez et al. 2007). In another study, a method has been investigated to temporarily inactivate the host cell restriction machinery by heat treatment of the cells prior to electroporation to enable efficient transformation of Staphylococcus carnosus (Löfblom et al. 2007). Earlier, Gowrishankar et al. (1999) have characterized the effects of high voltage electric fields on the barrier properties of human skin resulting in structural changes by using high voltage pulses through exponential pulser (Electroporation System 600, BTX Industries, San Diego, CA).

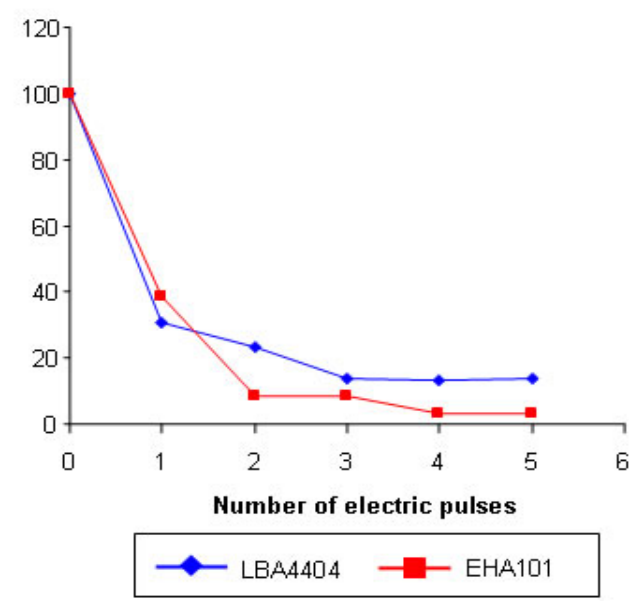

Figure 1. Comparison of relative viability of competent cells as a function of number of electric pulses.

With the advancement of plant biotechnology, Agrobacterium-mediated transformation has gained enough momentum, as it is relatively inexpensive, well-studied, simple technique manipulated from a natural process. However, in few studies (Shen and Forde, 1989; Mersereau et al. 1990) very limited work has been reported for improving electroporation efficiency of $A$. tumefaciens. The fact that electroporation efficiency is still much lower in Agrobacterium than E. coli indicates the need for further studies. Mersereau et al. (1990) reported the effect of voltage and Shen and Forde (1989) investigated both pulse voltage and length, while in this study we have analyzed the effect of multiple electric pulses on electroporation efficiency in Agrobacterium. The results of this study indicate that increase in number of electric pulses can improve the electroporation efficiency in A. tumefaciens.

\section{MATERIALS AND METHODS}

\section{Competent cell preparation}

A single colony of either EHA101, LBA4404 was picked up and cultured overnight in $5 \mathrm{ml}$ Luria Bertani (LB) broth (Tryptone $10 \mathrm{~g} / \mathrm{L}$, Yeast extract $5 \mathrm{~g} / \mathrm{L}, \mathrm{NaCl} 10 \mathrm{~g} / \mathrm{L}$, $\mathrm{pH} 7.0$ ) at $28^{\circ} \mathrm{C}$ with $250 \mathrm{rpm}$ shaking. Three $\mathrm{ml}$ of this culture was shifted to $1 \mathrm{~L} \mathrm{LB}$ medium, and incubated at $28^{\circ} \mathrm{C}$ with $250 \mathrm{rpm}$ until the $\mathrm{A}_{600}$ was about 0.5 . The culture was centrifuged at $3500 \mathrm{x}$ g for $15 \mathrm{~min}$ at $4^{\circ} \mathrm{C}$. The pellet was resuspended/washed with $15 \%$ glycerol in Nanopure water. After washing the bacteria were again pelleted. All the steps were performed on ice. This process of washing was repeated thrice. After final washing the pellet was divided into $50-100 \mu \mathrm{l}$ aliquots and stored at $-80^{\circ} \mathrm{C}$.

\section{Viability testing}

For the analysis of cell viability suitable dilutions of competent cells were spread on LB plate (Tryptone 10 g/L, Yeast extract 5 g/L, NaCl 10 g/L, Agar 10 g/L, pH 7.0) for counting number of cells. Similar procedure was adopted for counting cell viability after every electric pulse. Colony forming units were recorded for later comparisons.

\section{Transformation of EHA101 and LBA4404}

For electroporation $25 \mu \mathrm{l}$ competent cells of the Agrobacterium strains (EHA101 or LBA4404) were suspended between two electrodes spaced by $0.15 \mathrm{~cm}$. Electroporation was carried out with an electric pulse of $20.0 \mathrm{kV} / \mathrm{cm}$ and pulse length of $\sim 10 \mathrm{~ms}$ (Cell-Porator ${ }^{\circledR}$ by Life Technologies). Number of high voltage pulses ranged from 1 to 5 for each strain, with $\sim 15$ seconds inter-pulse duration. After each transformation the bacterial cells were resuscitated by suspending in $1 \mathrm{ml}$ of liquid LB media and subsequent incubation at $28^{\circ} \mathrm{C}$ with $250 \mathrm{rpm}$ shaking, before spreading on the LB plates. In all transformation experiments pCAMBIA1301 was used for electroporation. Screening of different transformants was performed on LB medium containing $50 \mu \mathrm{g} / \mathrm{ml}$ kanamycin and $50 \mu \mathrm{g} / \mathrm{ml}$ hygromycin.

\section{Confirmation of transformation}

Plasmid was isolated from positive clones. Polymerase chain reaction (PCR) was carried out to confirm the transformation using plasmid DNA as template and a pair of primers designed in sequence of hygromycin gene present on pCAMBIA1301. The PCR conditions used for the amplification of 700 bp fragment included, a PAD (Pre 
Amplification Denaturation) at $94^{\circ} \mathrm{C}$ for 5 min followed by 35 cycles at $94^{\circ} \mathrm{C}$ for $45 \mathrm{sec}, 52^{\circ} \mathrm{C}$ for $45 \mathrm{sec}$ and $72^{\circ} \mathrm{C}$ for $50 \mathrm{sec}$, with a final extension at $72^{\circ} \mathrm{C}$ for $20 \mathrm{~min}$.

\section{Hyg F: 5' GCTCCATACAAGCCAACCAC 3'}

\section{Hyg R: 5' CGAAAAGTTCGACAGCGTCTC 3'}

PCR results were further confirmed by restriction digestion using XhoI. Data were analyzed by one way ANOVA.

\section{RESULTS AND DISCUSSION}

The term electroporation is used to describe the phenomenon that accompanies exposure of cells to transmembrane electrical pulses. Electroporation yields reversible and irreversible permiabilization of the cell membrane as a function of electrical pulse voltage parameters i.e. amplitude, length, shape of the pulse, and cell type and developmental stage. Since the first report on gene transfer by electroporation (Neuman et al. 1982), it has become a standard method for transfection of cells (Hapala, 1997). Electroporation has several advantages. It is technically simple, can be used to treat whole population of cells, has broad application for transfer of any macromolecule, provides greater efficiency of transfection for many cell lines, and can be applied equally successfully to prokaryotic and eukaryotic cells (Lurquin, 1997). Nevertheless, it needs to empirically determine through extensive studies, the conditions for efficient transfection for each cell type (Andreason, 1993). There are few reports about electroporation mediated transformation of Agrobacterium, despite the fact that it has gained tremendous importance for being a natural genetic engineer of plants and is being used very effectively for plant transformation for the nearly three decades. Keeping in view the importance and efficiency of this simple plant transformation system, this study was designed to improve electroporation mediated DNA uptake in Agrobacterium.

\section{Confirmation of transformation by PCR and restriction digestion}

In this study the commonly used strains of Agrobacterium tumefaciens (LBA4404 and EHA101) were used. Competent cells of these strains were transformed by pCAMBIA 1301 (11.8 kb) in cell porator. Plasmid uptake was confirmed by PCR and restriction digestion of the isolated plasmid. PCR generated a 700 bp fragment from hygromycin resistance gene from positives clones, while restriction digestion with XhoI generated a $1 \mathrm{~kb}$ fragment from pCAMBIA 1301 as seen on $1 \%$ agarose gel in TAE buffer.

\section{Comparison of cell viability}

Irreversible permiabilization of cells results in leakage of cell content and ultimate death. It was therefore important to determine the viability in response to increase in number of pulses. In this study major decline in cell survival was observed after first high voltage pulse, similar effect has been observed by many investigators in other bacterial species (Garg et al. 1999). Further but slight decrease was observed after second pulse. However the viability remained almost unchanged in response to further shocks (Figure 1) in both strains.

As the viability curves under variable pulse regime remained somewhat similar, this parameter is not expected to influence the relative kinetics differences of plasmid uptake in different strains. Moreover, increasing number of pulses should have no contribution whatsoever, in the DNA uptake after second pulse.

These results indicated that different cell types vary in their responses to electric pulse which may be due to differences in membrane makeup and cell wall thickness, structure, and density. There are reports about the effect of varying pulse length duration for electroporation resulting in differences in efficiency which were correlated to the cell viability (Liang and Lee, 1998). It was also noted that an increase in the pulse duration beyond 10 ms resulted in a 20 fold reduction in transformants competence in $R$. leguminosarum (Garg et al. 1999). Keeping in view these reports, rather than further increase in these parameters, multiple electric pulses were employed at $20 \mathrm{kV} / \mathrm{cm}$ at 10 ms. This procedure resulted in a pronounced decrease in cell viability after first pulse, however, it remained nearly constant after second pulse. Thus the strategy of multiple pulses appeared to have a distinct advantage over increase either in pulse voltage or duration.

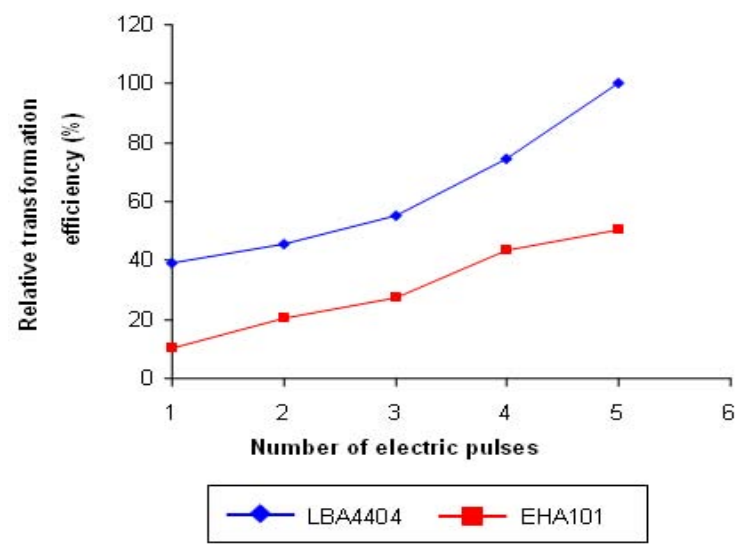

Figure 2. Comparison of relative transformation efficiencies in LBA4404 and EHA101 with increase in number of electric pulses.

\section{Comparison of transformation efficiencies}

The highest transformation efficiency observed in LBA4404 after five electric pulses was taken as reference while transformation efficiency for EHA101 was calculated accordingly. It was observed that with increase in the number of electric pulses, transformation efficiency increased gradually in both the strains. When compared with single pulse, efficiency increased to about 2.5 times in 
LBA4404 and five times in EHA101 after five electric pulses. In both these strains the increase was nearly linear (Figure 2).

Electric field strength (amplitude) and pulse length (duration) of discharge waveform are important effectors of electroporation. Increase in electric field strength (12.5 to $20 \mathrm{kV}$ ) for maximizing the transformation in Pediococcus acidilactici was reported by Rodríguez et al. (2007). Transformation in Agrobacterium has already been investigated using variable voltage and pulse duration (Mersereau et al. 1990). However we reported another aspect i.e. increase in number of pulses, which results in considerable increase in DNA transformation efficiency at peak pulse voltage and duration used for single pulse.

\section{REFERENCES}

ANDREASON, Grai L. Electroporation as a technique for the transfer of macromolecules into mammalian cell lines. Methods in Cell Science, June 1993, vol. 15, no. 2, p. 5662.

CHEN, Ding-Qiang; HUANG, Shao-Song and LU, YongJun. Efficient transformation of Legionella pneumophila by high-voltage electroporation. Microbiological Research, July 2006, vol. 161, no. 3, p. 246-251.

GARG, Bindu; DOGRA, Romesh C. and SHARMA, Parveen K. High-efficiency transformation of Rhizobium leguminosarum by electroporation. Applied and Environmental Microbiology, June 1999, vol. 65, no. 6, p. 2802-2804.

GOWRISHANKAR, Thiruvallur R.; PLIQUETT, Uwe and WEAVER, James C. Changes in skin structure and electrical properties following high voltage exposure. Annals of the New York Academy of Science, November 1999, vol. 888, no. 1, p. 183-194.

HAPALA, I. Breaking the barrier: methods for reversible permeabilization of cellular membranes. Critical Reviews in Biotechnology, 1997, vol. 17, no. 2, p. 105-122.

LIANG, Ching-Chou and LEE, Wen-Chien. Characteristics and transformation of Zymomonas mobilis with plasmid pKT230 by electroporation. Bioprocess and Biosystems Engineering, August 1998, vol. 19, no. 2, p. 81-85.

LÖFBLOM, J.; KRONQVIST, N.; UHLÉN, M.; STAHL, S. and WERNÉRUS, H. Optimization of electroporationmediated transformation: Staphylococcus carnosus as model organism. Journal of Applied Microbiology, March 2007, vol. 102, no. 3, p. 736-747.

LURQUIN, P.F. Gene transfer by electroporation. Applied Biochemistry and Biotechnology - Part B Molecular Biotechnology, February 1997, vol. 7, no. 1, p. 5-35.
MERSEREAU, M.; PAZOUR, G.J. and DAS, A. Efficient transformation of Agrobacterium tumefaciens by electroporation. Gene, 1990, vol. 90, no. 1, p. 149-151.

MYERS, Anna K. and TISA, Louis S. Effect of electroporation conditions on cell viability of Frankia Eul1c. Plant and Soil, July 2003, vol. 254, no. 1, p. 83-88.

NEUMAN, E.; SCHAEFER-RIDDER, M.; WANG, Y. and HOFSCHNEIDER, P.H. Gene transfer into mouse lyoma cells by electroporation in high electric fields. EMBO Journal, 1982, vol. 1, no. 7, p. 841-845.

RHEE, M.S.; KIM, J.-W.; QIAN, Y.; INGRAM, L.O. and SHANMUGAM, K.T. Development of plasmid vector and electroporation condition for gene transfer in sporogenic lactic acid bacterium, Bacillus coagulans. Plasmid, July 2007, vol. 58, no. 1, p. 13-22.

RODRÍGUEZ, M. Carmen; ALEGRE, M. Teresa and MESAS, Juan M. Optimization of technical conditions for the transformation of Pediococcus acidilactici P60 by electroporation. Plasmid, July 2007, vol. 58, no. 1, p. 4450 .

SHEN, Wen-Jun and FORDE, Brian G. Efficient transformation of Agrobacterium spp. by high voltage electroporation. Nucleic Acids Research, October 1989, vol. 17, no. 20, p. 8385.

TURGEON, Nathalie; LAFLAMME, Christian; HO, Jim and DUCHAINE, Caroline. Elaboration of an electroporation protocol for Bacillus cereus ATCC 14579. Journal of Microbiological Methods, December 2006, vol. 67 , no. 3 , p. 543-548. 